\title{
The relationship between body composition and vitamin $E$ status in females aged 18-40 years
}

\author{
A. Mullee, M. S. Mulhern, J. M. W. Wallace and J. J. Strain \\ Northern Ireland Centre for Food and Health (NICHE), University of Ulster, Coleraine BT52 ISA, UK
}

Obesity is an independent risk factor and a major contributor to morbidity and mortality in the general population ${ }^{(1)}$. The condition is associated with alterations in both lipid metabolism and adipose tissue distribution ${ }^{(2)}$, which may affect plasma concentrations of the fat soluble vitamin E. Vitamin E, found in the diet in the form of four tocopherols $(\alpha-, \beta-, \gamma-$ and $\delta$-) four tocotrienols $(\alpha-, \beta-, \gamma-$ and $\delta$-), is an important antioxidant. Previous studies investigating the relationship between $\alpha$-tocopherol, and $\%$ body fat have shown conflicting results, one study finding a positive correlation ${ }^{(3)}$ and the other no significant correlation ${ }^{(4)}$. The aim of this study was to determine whether plasma $\alpha$ - and $\gamma$-tocopherol concentrations were associated with measures of adiposity in apparently healthy females between 18 and 40 years of age.

A total of 32 normal weight (BMI $18.5-24.9 \mathrm{~kg} / \mathrm{m}^{2}$ ) and 22 overweight/obese (BMI $25-39 \mathrm{~kg} / \mathrm{m}^{2}$ ) volunteers participated in the study. Plasma $\alpha$ - and $\gamma$-tocopherol were measured by HPLC (Waters Ltd, Dublin, Ireland). Serum lipids were measured using standard commercial kits. Body composition was analysed using BodPod ${ }^{\circledR}$ by air displacement plethysmography.

\begin{tabular}{lccccc}
\hline & \multicolumn{2}{c}{ Normal $(\boldsymbol{n}=\mathbf{3 2})$} & & \multicolumn{2}{c}{ Overweight/obese $(\boldsymbol{n}=\mathbf{2 2})$} \\
\cline { 2 - 3 } \cline { 5 - 6 } & Mean & SD & & Mean & 5.02 \\
\hline$\alpha$-tocopherol $(\mu \mathrm{mol} / \mathrm{l})$ & 23.98 & 3.51 & 23.91 & 0.63 \\
$\alpha$-tocopherol/cholesterol $(\mu \mathrm{mol} / \mathrm{mmol})$ & 5.24 & 0.49 & & 5.17 & $1.19-2.30$ \\
$\gamma$-tocopherol $(\mu \mathrm{mol} / \mathrm{l})^{?} \psi$ & 1.57 & $1.36-1.86$ & & 1.53 & $0.27-0.43$ \\
$\gamma$-tocopherol/cholesterol $(\mu \mathrm{mol} / \mathrm{mmol})^{\psi}$ & 0.37 & $0.27-0.49$ & & 0.37 & $4.27^{* *}$ \\
Percent fat $(\%)$ & 26.3 & 6.62 & 35.9 & $23.4-27.8^{* *}$ \\
Fat mass $(\mathrm{kg})^{? ?} \psi$ & 14.9 & $12.7-19.7$ & & 26 & $5.05^{*}$ \\
Fat free mass $(\mathrm{kg})$ & 44.1 & 4.72 & 48.1 & $8.89-10.42$ \\
Fat mass index $\left(\mathrm{kg} / \mathrm{m}^{2}\right)^{\psi}$ & 5.76 & $4.69-7.12$ & & 9.53 & \\
\hline
\end{tabular}

${ }^{\psi}$ Results expressed as medians and IQR.

Mean values were significantly different from those of normal weight.

$* P=0.001 ; * * P=0.001$ from independent samples T-tests.

There were no significant differences in plasma $\alpha$ - and $\gamma$-tocopherol and lipid concentrations between the normal weight and the overweight obese groups. No significant correlations were found between plasma tocopherol status and measures of adiposity. In conclusion, vitamin E status does not appear to be affected by increased adiposity in females with a BMI of $25-39 \mathrm{~kg} / \mathrm{m}^{2}$ compared to normal weight females. Due to a limited sample size, further research is warranted to investigate if obesity affects vitamin E status.

1. Whitlock G, Lewington S, Sherliker P et al. (2009) Lancet 373, 1083-1096.

2. Kissebah AH, Vydelingum N, Murray R et al. (1982) J Clin Endocrinol Metab 54, 254-260.

3. Grolier P, Boirie Y, Levadoux E et al. (2000) Br J Nutr 84, 711-716.

4. Wallstrom P, Wirfalt E, Lahmann PH et al. (2001) Am J Clin Nutr 73, 777-785. 